\title{
Analysis of two Leveling Courses in Chemistry: objectives, methodology, assessments and future prospects
}

\author{
Arroyo-de Dompablo, M. Elena ${ }^{a}$ and Ibáñez-González, M. Joséb \\ ${ }^{a}$ Departamento de Química Inorgánica, Facultad de Ciencias Químicas, Universidad \\ Complutense de Madrid, Spain ${ }^{\text {b}}$ Departamento de Ingeniería Química, Escuela Superior de \\ Ingeniería, Universidad de Almería, Spain
}

\begin{abstract}
The purpose of this report is to analyze different aspects of two leveling courses in Chemistry offered to entry-level students in the Degree in Geology (Universidad Complutense de Madrid) and in the Degree in Agricultural Engineering (Universidad de Almería). We comparatively analyze the motivations for offering the course, its aims and objectives, the course design, methodology, assessment and finally the achievements of the course in both universities. The assessment of learning process is done through quizzes at the beginning and at the end of the courses. Voluntary and anonymous surveys show that the students are very satisfied with the courses. In the future, the aim is to improve the learning methodology in order to achieve greater student motivation.
\end{abstract}

Keywords: Chemistry; leveling course; e-learning; flipped class 


\section{Introduction}

Chemistry is commonly seen as a "central science" (Brown, LeMay, Bursten, Murphy, \& Woodward, 2009), so that the mastery of its concepts is essential for future university courses in all sciences and in many engineering majors. Unfortunately, the present Spanish educational system does not guarantee that the students accessing the higher education level possess the required mastery of chemistry. Several research studies directly address the issue of high school preparation in connection with college performance in Chemistry (see for instance (Tai, Sadler, \& Loehr, 2005)). In this scenario, leveling college courses can be designed to give the students a solid foundation in Chemistry, prior to face the Chemistry courses at the University. Therefore, leveling courses could be defined as the courses taken at the beginning of the first terms by a student before he/she begins their study of Chemistry at the level of the first course taught in the corresponding major. There are diverse formats for these leveling courses, going from traditional in classroom lectures to full $e$-learning courses.

A variety of different entry-level sequences of introductory Chemistry is being offered alongside Spanish universities. Each one is designed for a different target audience, usually differentiated by major. The inter-university framework is a good platform for further development of the leveling courses in Chemistry. In this communication, we analyze the courses of leveling in Chemistry imparted in-classroom in the Degrees in Geology at the Universidad Complutense de Madrid (UCM), and through the $e$-learning platform in the Degree in Agricultural Engineering at the Universidad de Almería (UAL). We will comparatively expose the contents, teaching methodology and evaluation procedures of both courses. The aim of this inter-university collaborative work is to improve the quality of the leveling courses in Chemistry.

The leveling course in Chemistry for the Degree in Geology (UCM) consists of 15 hours of traditional in-classroom lectures, divided in daily sessions of $1.5 \mathrm{~h}$. The entire course is covered in the 10 days before the starting of the regular lectures. The students who accomplish successfully the course are awarded with 1.5 ECTS (European Credit Transfer System). The leveling course in Chemistry for the Degree in Agricultural Engineering (UAL) is encompassed in the subject of Chemistry I (6 ECTS, 1 semester). The leveling course is offered to all the students through the $e$-learning platform. Chemistry I consists of 45 hours, 24 hours in the classroom and 19 hours in the laboratory. The first two hours of each unit comprise a review of basic concepts. 


\section{Methodology}

The design of the leveling courses requires a careful selection of the teaching contents. Our starting point was the program of the subject of Chemistry offered in the last year of high school (Ministerio de Educación, 2015). Figure 1 shows the contents that cover the following topics: periodic table, atomic structure, chemical bonds, chemical reactions, dissolutions, thermodynamics, kinetics and chemical equilibrium. As basic criteria for specific course design we have considered the major, the level of the students and the length of the course. Depending on the major each course is taught at a different level of difficulty for a particular topic, requiring different levels of ability, motivation, and effort, as well as different levels of high school preparation. The length of the leveling course is a limiting factor. In the leveling courses under analysis the lessons have been reorganized according to the majors (Degree in Geology and Degree in Agricultural Engineering), taking into account the entry level of the students, and the course length. The respective programs can be seen in figure 1 .

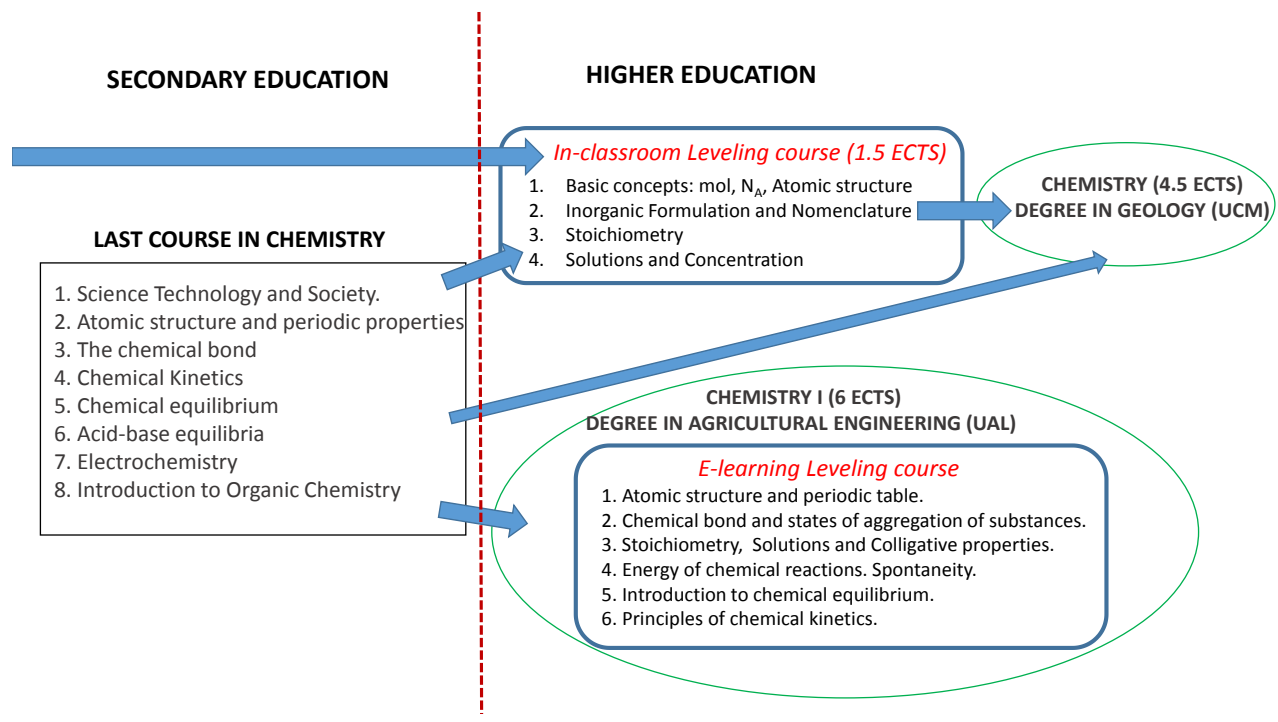

Figure 1. Chart of contents in a high school Chemistry course and in the leveling-courses in Chemistry at the Degree in Geology (UCM) and Degree in Agricultural Engineering (UAL)

A wide range of teaching support and resource materials must be provided to the students. In the two leveling courses under analysis, faculty and teaching assistants have collaborated to prepare such material. Appropriate PowerPoint presentations, some audiovisuals and 
self-assessments have been developed for both the in-class or $e$-learning courses at the Department of Inorganic Chemistry (UCM, 2014) and the Department of Engineering (UAL), respectively.

The phases of control and evaluation test the validity of the leveling-courses, throwing results on the attainment of the educational objectives. In the leveling-courses evaluation is mostly done using surveys and multi-choice quizzes. These questionnaires have been designed taking into account the different nature of the courses, in either classroom, or $e$ learning formats. The questionnaires check the level of knowledge in Chemistry acquired by the students but also reflect their opinion about the course.

\section{Results}

\subsection{Traditional in-classroom course. Degree in Geology/Engineering Geology (UCM)}

Students can access the major conducting to the Degree in Geology (UCM) with the minimum mark of the university access exam (5 over 14). Most of these students have a poor level in Chemistry. The leveling course in Chemistry is specially designed for students who did not select Chemistry as a subject in the last year of secondary education, although students who desire to reinforce their skills are also accepted. A maximum of 30 students can enroll this course. The leveling course aims providing the very basic concepts of Chemistry, which are introduced in four lessons (see figure 1).The material is delivered to the students as Power Point presentations across the $e$-learning platform the day before the course starts. Along the ten in-class sessions (1.5 hour long), the professor explains the main concepts, ask for individual problem solving and corrects the problems in the backboard. Flipped classroom methodology (Mason, Shuman, \& Cook, 2013; Missildine, Fountain, Summers, \& Gosselin, 2013) is encouraged, by having students reading selected texts outside of the class, watching supplemental videos, or solving additional problems. However, so far the students show almost no interest in these additional activities.

To measure student subject/matter learning, we used multiple-choice exams. To evaluate the starting level of the students, the first day of class they anonymously solve a quiz (five questions). A second quiz consisting of seven questions, different from those in the first survey, is run at the end of the course. Figure 2 compares the marks obtained for both quizzes, in two consecutive academic years. The percentage of students who correctly answered the questions was significantly higher in the second quiz versus the first.

To measure student perceptions of the classroom, we used a survey (not show for conciseness). The instructor asks the students to communicate anonymously their point of view about the different academic aspects and guidance of the leveling course, through forms filled out in the classroom at the end of the course. In general, the acceptance of the 
course is excellent. There are discrepancies regarding the level of the lectures, which is low for some students and high for others (obviously depending on their previous high-school skills). The most valued aspect is the opportunity offered by the course to gradually integrate into the Faculty, and to socialize, in the students' words "make friends".
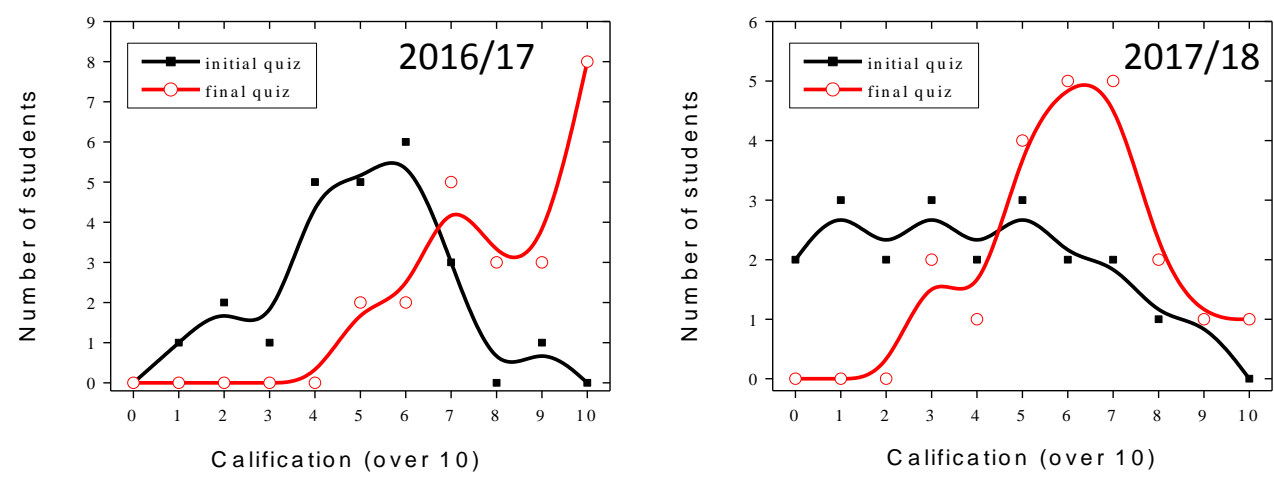

Figure 2. Results of the quizzes in the leveling-courses in Chemistry at the Degree in Geology (UCM). The total number of students taking the course was 24 in 2016/17 and 21 in 2017/2018

\section{2. e-learning course. Degree in Agricultural Engineering (UAL)}

In general, these are students possessing an acceptable level of Chemistry and Mathematics. Only an underrepresentative minority of students did not take a Chemistry course in the last year of secondary education. Therefore, it has not been considered necessary to design a separate leveling-course, but supplying some introductory material before the beginning of the classes of the subject Chemistry I. Thus, lessons of the leveling-course focus on reviewing the concepts that will be later expanded in the Chemistry I course (see figure 1). Around 95-135 students are enrolled in this subject.

The leveling course is offered in the $e$-learning platform, applying the flipped learning methodology (Mason, Shuman, \& Cook, 2013; Missildine, Fountain, Summers, \& Gosselin, 2013), creating a flexible learning environment, empathizing the synergy between group and individual activities and enhancing collaborative learning. The teachers have developed comprehensive, helpful, and interesting chemistry lectures in a series of PowerPoint presentations and audiovisual material, such as YouTube videos or videos made by teachers using Active Presenter software and a Wacom Intuos Pen with a touch small table. In addition, at least 2 hours of classroom sessions are provided for problembased learning. In the classroom, the professor comments on a PowerPoint reminder and distributes the exercises related to the topic to the students working in informal collaborative groups during their resolution. After resolution, a student from the group is 
chosen to resolve the problem on the blackboard. The mark obtained by the student, will be the score of all group. This methodology assured that all students from a group take part in the problem resolution.

Students (approximately 30) voluntarily answer a survey in the Quick test format about their degree of satisfaction with the leveling course. Figure 3 shows a Quick test's answers focused on cooperative learning in the classroom. From the results of the test, it is clear that everyone likes group learning, since it allows them to get to know their classmates. They dislike public speaking. Thus, solving exercises on the blackboard "overwhelms" them. About the audiovisual material (mp4), which has been offered in the course, the opinions were more varied: from "not being useful", to "being useful but not listening well" and to "being useful". The percentage of students passing the Chemistry I subject increased in 30 $\%$ after implementing the leveling course.

\section{¿How do you like cooperative learning in the classroom?}

\begin{tabular}{|l}
\hline + It gives me the chance to meet classmates \\
+ The experience has been very positive for my \\
personal development. I discovered that discussing \\
with others and solving exercises in the blackboard \\
help me to cope with my shyness \\
+ Being part of a teamwork makes easier solving the \\
exercises. \\
- I really dislike speaking in public \\
- Solving exercises on the blackboard makes me feel \\
under too much pressure \\
- I find hard assuming the responsibility of \\
contributing to my group's mark. What if I am not \\
good enough?
\end{tabular}

Figure 3. Summary of the students answers to the anonymous quick test in the leveling-course in Chemistry I at the Degree in Agricultural Engineering (UAL)

\section{Discussions}

The traditional in-classroom course seems more appropriate for low-level students. During class time, the professor continually observes their students, providing them with feedback relevant in the moment, and assessing their work. This course is scheduled before the official semester starts. The small number of students in the leveling course facilitates the mentoring work of the professor, who has the possibility of helping the students to integrate fully into the university community, stimulating them to approach their studies with 
advantage, and inducing an attitude of responsibility over their successes and failures in the forthcoming high education. As disadvantage, this course is quite intensive; limited to a short period of time (10 days) which makes difficult for the students to fully acquire the concepts. Collaborative work is also complicated to conduct in that short period. The flipping class methodology would add dynamism to this course. So far, our attempts in that direction have negligible impact on the students.

The $e$-learning course allows the professor to cover more material, and in accordance, the student must invert a higher level of work. The success of the course is deeply based on the self-learning effort developed by the student. While this is highly positive for motivated students, for the students with poor motivation this methodology is less effective than the traditional in-class lectures. The professor should find the way to get the student to work at home before going to the in-class group activities. The quality of the audiovisual material is essential in the $e$-learning methodology. We are currently working in a better audiovisual material (UAL, 2016), using the Camtasia Studio 8, a software well suited for academicians (Carlson, 2009; Schumacher \& Thurkettle, 2007). Learning methodologies applying gamification (Dominguez et al., 2013; Hanus \& Fox, 2015) will be included in the future.

The surveys reflect that the students welcome the leveling courses in Chemistry. The students are satisfied with either the in-classroom or the $e$-learning course. They find these courses reinforce their self-confidence, knowledge of the subject, and position them well to succeed in the Chemistry courses in their respective degrees. However, from an academic perspective, there is no solid evidence to sustain that the students who enrolled in the leveling course perform better than their peers do. More investigations should be performed in that direction.

\section{Conclusions}

We have analyzed two different leveling courses in Chemistry. E-learning courses and traditional in-classroom courses have both advantages and disadvantages. The results let us conclude that an effective course design depends critically on the entry-level of the students. A key issue to reinforce in the future is the quality of the audiovisual material provided to the students. We expect that material based on gamification will also influence positively the motivation of the students. In future we will also design strategies to evaluate the impact of the leveling course on performance in the Chemistry subjects. Overall, students who enrolled and follow the leveling-courses are very satisfied with their academic progress and personal assessments. 


\section{Acknowledgements}

Authors thank financial support from Universidad de Almería across the "Convocatoria de Grupos Docentes para la Creación de Materiales Didácticos en la Universidad de Almería" program and Prof. J. Luque (Vicedean for Studies and Quality, Faculty of Geology, UCM) for his careful reading of this manuscript.

\section{References}

Brown, T. E., LeMay, H. E., Bursten, B. E., Murphy, C., \& Woodward, P. W. (2009). Chemistry: The Central Science.

Carlson, K. (2009). Delivering Information to Students 24/7 with Camtasia. InformatioTechnology and Libraries, 28(3), 154-156. doi:10.6017/ital.v28i3.3223

Dominguez, A., Saenz-de-Navarrete, J., de-Marcos, L., Fernandez-Sanz, L., Pages, C., \& Martinez-Herraiz, J.-J. (2013). Gamifying learning experiences: Practical implications and outcomes. Computers \& Education, 63, 380-392. doi:10.1016/j.compedu.2012.12.020

Hanus, M. D., \& Fox, J. (2015). Assessing the effects of gamification in the classroom: A longitudinal study on intrinsic motivation, social comparison, satisfaction, effort, and academic performance. Computers \& Education, 80, 152-161. doi:10.1016/j.compedu.2014.08.019

Mason, G. S., Shuman, T. R., \& Cook, K. E. (2013). Comparing the Effectiveness of an Inverted Classroom to a Traditional Classroom in an Upper-Division Engineering Course. Ieee Transactions on Education, 56(4), 430-435. doi:10.1109/te.2013.2249066

Ministerio de Educación, C. y. D. (2015). Real Decreto 1105/2014, de 26 de diciembre, por el que se establece el currículo básico de la Educación Secundaria Obligatoria y del Bachillerato. B.O.E. 13 de enero de 2015.

Missildine, K., Fountain, R., Summers, L., \& Gosselin, K. (2013). Flipping the Classroom to Improve Student Performance and Satisfaction. Journal of Nursing Education, 52(10), 597-599. doi:10.3928/01484834-20130919-03

Schumacher, G., \& Thurkettle, M. A. (2007). Camtasia studio: A teaching tool for academicians and clinicians. Cin-Computers Informatics Nursing, 25(3), 130-134. doi:10.1097/01.NCN.0000270038.29788.f1

Tai, R. H., Sadler, P. M., \& Loehr, J. F. (2005). Factors influencing success in introductory college chemistry. Journal of Research in Science Teaching, 42(9), 987-1012. doi:10.1002/tea.20082

UAL. (2016). Universidad Compluense de Almería. Convocatoria de Grupos Docentes para la Creación de Materiales Didácticos en la Universidad de Almería. "Preparación de material audiovisual en química”.

UCM. (2014). Universidad Compluense de Madrid. Proyectos de Innovación y Mejora de la Calidad Docente Curso de nivelación de Química para los Grados en Geología e Ingeniería Geológica-PIMCD230. 